\title{
Effect of autologous platelet rich plasma on thin endometrium in frozen thawed embryo transfer
}

\author{
Adaboina Anitha*, Burri Sandhya Rani
}

Department of Obstetrics and Gynecology, Laxmi Narasimha Hospital, Hanamkonda, Warangal, Telangana, India

Received: 16 December 2019

Revised: 16 January 2020

Accepted: 24 January 2020

\section{*Correspondence:}

Dr. Adaboina Anitha,

E-mail: anithaadoboina@gmail.com

Copyright: () the author(s), publisher and licensee Medip Academy. This is an open-access article distributed under the terms of the Creative Commons Attribution Non-Commercial License, which permits unrestricted non-commercial use, distribution, and reproduction in any medium, provided the original work is properly cited.

\begin{abstract}
Background: Endometrium is one of the main factors in implantation and pregnancy. Some of the assisted reproductive technology treatment (ART) cycles get cancelled due to inadequate endometrial growth. This study was conducted to evaluate the effectiveness of PRP (platelet rich plasma) in the treatment of thin endometrium and its outcome on pregnancy and live birth rates.

Methods: This study was a prospective cohort which was conducted from January 2018 to December 2018 at Laxmi Narasimha Hospital, Warangal, Telangana State. 30 patients with history of inadequate endometrial growth in frozen thawed embryo transfer cycles were recruited into the study. Intrauterine infusion of PRP was performed. Endometrial thickness was assessed.

Results: 30 women were recruited in the study data of the 24 women were collected. Live birth was seen in 5 patients in the week range of $37 \pm$ to $37 \pm 5$ and average EMT in $\mathrm{mm}$ was 7.8 , abortion was seen in 3 patients in the week range of 6 to $8 \pm 2$ and average EMT in mm was 7.4 , chemical pregnancy was seen in 2 patients in the week range of 6 and average EMT in mm was 7.2 and number of women who were not pregnant were 14 and average EMT in mm was 7.0. Live birth was observed in $21 \%$ of the patients, abortion was observed in $13 \%$, chemical pregnancy was seen in $9 \%$ and women who were not pregnant were $58 \%$.

Conclusions: Ability of autologous PRP to restore the endometrial receptivity of damaged endometrium has some aspects other than increasing the EMT.
\end{abstract}

Keywords: Assisted reproductive technology treatment, Autologous platelet rich plasma, Endometrial thickness

\section{INTRODUCTION}

The technology has rapidly evolved and the pregnancy rate with IVF-ET has increased significantly, since the in vitro fertilization and embryo transfer was introduced. ${ }^{1}$ In treating infertility patients, the problem which is unsolved is thin or damaged endometrium. ${ }^{2,3}$ To restore endometrial receptivity, several treatments were attempted which included exogenous estrogen administration, vitamin E, vaginal sildenafil citrate and pentoxifylline. Patients who don't respond to the above treatment with refractory thin endometrium and do not have many options and an endometrium with a thickness of below $7 \mathrm{~mm}$ is non-optimal for implantation of embryo and is associated with a low pregnancy rate., ${ }^{4,5}$ With the help of cell proliferation there has been some progress in treating damaged or thin endometria including stem cell therapy. Low dose aspirin, intrauterine perfusion with granulocyte colony stimulating factor (G-CSF) have been used for thin endometrium but there isn't any proved evidences in this treatment (Barad et al, 2014, Chang et al, 2015, Eftekhar et al, 2013, Leboritz and Orrieto et al, 2014, Xu et al, 2015). Autologous platelet rich plasma (PRP) has been 
used since 1970's and it has become popular in the 1990's. Platelets play an important role in hemostasis and is a crucial blood component. The $\alpha$-granules inside the platelets secrete growth factors, cytokines and chemokines which help in the healing process. ${ }^{6}$ Paracrine effects on myocytes, tendon cells, mesenchymal stem cells, chondrocytes, osteoblasts, fibroblasts, and endothelial cells, stimulating cell migration, cell proliferation, angiogenesis and further inducing tissue regeneration is done by secreted proteins. In 2015, the first study on PRP for treating human thin endometrium in-vivo. In this study, the platelet concentration and type of PRP that was used and the effect on refractory thin endometrium regarding pregnancy and live birth rates was studied.

\section{METHODS}

This study was a prospective cohort which was conducted from January 2018 to December 2018 at Laxmi Narasimha Hospital, Warangal, Telangana, India.

\section{Inclusion criteria}

- Women who had undergone two or more failed IVF cycles and refractory thin endometrium, patients with age of 20 to 45 years, endometrial thickness of lesser than $7 \mathrm{~mm}$ on the human chorionic gonadotropin administration day in the fresh ET cycles or the end of estrogen priming day in frozen ET cycles in all of previous cycles, two or more failed IVF cycles.

\section{Exclusion criteria}

- Hematologic disorders, hemoglobin levels lesser than $9 \mathrm{~g} / \mathrm{dl}$, platelet count of less than 1 lakhs per microliter, auto immune disorder, chromosomal abnormality in the patient or spouse, peripheral NK cell proportion of less than or equal to $12 \%$, BMI of less than or equal to $30 \mathrm{~kg} / \mathrm{m}^{2}$, uncontrolled endocrine on other medical conditions such as thyroid diseases.

\section{Autologous PRP preparation}

A total $18 \mathrm{ml}$ of venous blood was drawn from patients on every PRP administration. The blood samples were moved into an aseptic PRP centrifuge kit and centrifuged at 1017 gyrations for 4 mins. The buffy coating and plasma were collected and 0.7 to $1 \mathrm{ml}$ of PRP was produced and infused into uterine cavity.

\section{Autologous PRP administration and ET}

All patients signed on informed written consent. Hysteroscopic examination was performed before the cycle, if it had not been done previously. Harmone replacement therapy (HRT) was performed for endometrial preparation in all participants. Estradiol valverate $6 \mathrm{mg} /$ day was started on the $2^{\text {nd }}$ and $3^{\text {rd }}$ day of the menstrual cycle and it was increased to $8 \mathrm{mg} /$ day on day 9 to 10 because of inadequate endometrial growth (< $7 \mathrm{~mm}$ ). PRP was performed on day 11-12 in all patients due to thin endometrium and it was repeated on day 1314. During the cycle, whenever the endometrial thickness was more than $7 \mathrm{~mm}$, suppository progesterone $400 \mathrm{mg}$ twice a day was started, and embryo transfer was carried out per embryonic stage. Estradiol valverate and progesterone supplementation were continued for 2 weeks after ET and if the serum BHCG was positive, harmone supplementation were continued until 12 weeks of gestation using SPSS software, version 24, the statistical analysis was performed. A p value of less than 0.05 was considered statistically significant.

\section{RESULTS}

A total 30 women were recruited in the study and 25 of them underwent ET. 2 patients underwent preimplantation genetic screening and abnormality in embryo was observed. 3 patients withdrew from the study because of personal reasons. Out of 25 patients, one patient was lost to follow up. The data of the remaining 24 women were collected.

Table 1: Demographic data.

\begin{tabular}{|c|c|c|}
\hline \multicolumn{2}{|c|}{ Parameters } & Baseline characteristics \\
\hline \multicolumn{2}{|c|}{ Age (years) } & $20-45$ \\
\hline \multicolumn{2}{|c|}{$\mathrm{BMI}\left(\mathrm{kg} / \mathrm{m}^{2}\right)$} & $19.2-28.4$ \\
\hline \multicolumn{2}{|c|}{ Failed IVF cycles } & $2-5$ \\
\hline \multicolumn{2}{|c|}{ Infertility duration } & 1.9-10.5 years \\
\hline \multirow{4}{*}{ Parity } & Term birth & $1-2$ \\
\hline & Preterm birth & 1 \\
\hline & Abortion & $1-4$ \\
\hline & Living birth & $1-2$ \\
\hline
\end{tabular}

The average age of the patients was 36.7 years. The mean duration of infertility in the 24 women was 6.2 years. The mean number of dilatation and evacuation was 1.5. The mean number of failed IVF cycles was 3. The mean EMT of the previous cycle hCG administration or the final estrogen priming day was $7.0 \mathrm{~mm}$ (Table 1).

Table 2: Results of autologous platelet rich plasma treatment.

\begin{tabular}{|llll|}
\hline Patients & $\begin{array}{l}\text { Obstetric result } \\
\text { Week } \\
\text { (Range) }\end{array}$ & Result & $\begin{array}{l}\text { EMT fina } \\
(\mathbf{m m}) \\
\text { average }\end{array}$ \\
\hline $1-5$ & $37 \pm 2-37 \pm 5$ & Live Birth & 7.8 \\
\hline $6-8$ & $6-8 \pm 2$ & Abortion & 7.4 \\
\hline $9-10$ & 6 & $\begin{array}{l}\text { Chemical } \\
\text { pregnancy }\end{array}$ & 7.2 \\
\hline $11-24$ & Not pregnant & Not pregnant & 7.0 \\
\hline
\end{tabular}

That live birth was seen in 5 patients in the week range of $37 \pm 2$ to $37 \pm 5$ and average EMT in mm was 7.8 , abortion was seen in 3 patients in the week range of 6 to $8 \pm 2$ and 
average EMT in mm was 7.4 , chemical pregnancy was seen in 2 patients in the week range of 6 and average EMT in mm was 7.2 and number of women who were not pregnant were 14 and average EMT in mm was 7.0 (Table 2).

Table 3: Results of autologous platelet rich plasma treatment.

\begin{tabular}{|ll|}
\hline Patients & Result \\
\hline $1-5$ & Live birth (21\%) \\
\hline $6-8$ & Abortion (13\%) \\
\hline $9-10$ & Chemical pregnancy (9\%) \\
\hline $11-24$ & Not pregnant (58\%) \\
\hline
\end{tabular}

That live birth was observed in $21 \%$ of the patients, abortion was observed in $13 \%$, chemical pregnancy was seen in $9 \%$ and women who were not pregnant were $58 \%$ (Table 3).

\section{DISCUSSION}

The objective of the study was to evaluate whether pregnancy outcomes of patients with refractory thin endometrium was improved by intrauterine administration of PRP. Live birth rate was observed in $21 \%$ of the patients in the present study. In Chang Y et al study, it was observed that after standard hormone replacement therapy (HRT), five women undergoing in vitro fertilization (IVF) with poor endometrial response still had thin endometrium $(<7 \mathrm{~mm})$ and had to cancel embryo transfer cycle. ${ }^{7}$ Intrauterine infusion of PRP was performed, in addition to HRT. From autologous blood by centrifugation, PRP was prepared and $0.5-1 \mathrm{ml}$ of PRP was infused into the uterine cavity on the $10^{\text {th }}$ day of HRT cycle. If endometrial thickness failed to increase 72 $\mathrm{h}$ later, PRP infusion was done 1-2 times in each cycle. Embryos were transferred when the endometrium thickness reached $>7 \mathrm{~mm}$. In Colombo GVL et al study, it was observed that eight patients with more than 3 cryotransfers cancelled because of failure of endometrial growth, defined as endometrium less than $6 \mathrm{~mm}$, with negative hysteroscopic screening for endometrial pathology, and with negative bacteriologic screening, before present and all previous treatment, were selected to undergo PRP treatment. ${ }^{8}$ In 7 out of 8 treatments, an endometrial thickness greater than $6.5 \mathrm{~mm}$ (mean 6.9 $\mathrm{mm}$ ) was reached, with endometrial three-layer pattern, before progesterone administration and embryo transfer was performed. In 6 out of 7 patients, who underwent embryo transfer, beta-HCG were positive, with 2 biochemical abortions, one miscarriage at 6-week pregnancy, two babies born and one drop-out. In this study, 8 patients had extraordinarily poor endometrial quality, and the endometrium was non-responsive to conventional estrogenic therapy, resulting in cycle cancellation. After application of PRP, the endometrial thickness was satisfactory in all the patients except one. Of these, beta-HCG was positive in 6 women, the pregnancy was progressing normally in 2 women, and one had an early miscarriage. In Molina A et al study, it was reported that endometrial thicknesses $>7 \mathrm{~mm}$ was reported with the first use; and in all cases, endometrial thicknesses > $9 \mathrm{~mm}$ were evident after the second administration. ${ }^{9}$ The entire study group qualified for embryo transfer at the blastocyst stage. We had $73.7 \%$ of positive pregnancy tests, of which $26.3 \%$ yielded live births; $26.3 \%$ ongoing pregnancies; $10.5 \%$ biochemical pregnancies; $5.3 \%$ anembryonic pregnancies and $5.3 \%$ had fetal death (16 weeks). Tandulwadkar SR et al, reported that the mean pre-PRP endometrial thickness (ET) was $5 \mathrm{~mm}$ which significantly increased to $7.22 \mathrm{~mm}$ post-PRP. ${ }^{10}$ There was a significant increase in vascularity, seen by the number of vascular signals seen on power Doppler, reaching the zones 3 and 4 of the endometrium. The positive beta human chorionic gonadotropin (hCG) rate was $60.93 \%$ and the clinical pregnancy rate was $45.31 \%$. A total of 13 women are in the second trimester, 13 are in the first trimester with a healthy intrauterine pregnancy, one patient had an ectopic gestation, three had blighted ova, two had missed abortions, and two biochemical pregnancies. Jang HY et al reported that $\mathrm{H}$ and $\mathrm{E}$ and $\mathrm{MT}$ staining confirmed significantly decreased fibrosis and increased cellular proliferation in the PRP-treated group, compared to the ethanol group. ${ }^{11}$ The endometrial areas in the ethanol and PRP-treated groups were 212.83 $\pm 15.84 \mu \mathrm{m}^{2}$ and $262.34 \pm 12.33 \mu^{2}(p=0.065)$. Significantly stronger IHC expression of cytokeratin, homeobox A10 (HOXA10), vascular endothelial growth factor (VEGF), and Ki-67 was found in the PRP-treated group, compared to the ethanol group. In real-time PCR analyses, interleukin-1 $\beta$ mRNA was down-regulated, while c-Kit mRNA was up-regulated, in the PRP-treated group, compared to the ethanol group.

\section{CONCLUSION}

The objective of the study was to evaluate whether pregnancy outcomes of patients with refractory thin endometrium was improved by intrauterine administration of PRP. Live birth was observed in $21 \%$ of the patients, abortion was observed in $13 \%$, chemical pregnancy was seen in $9 \%$ and women who were not pregnant were 58\%. Taking into the patient history consideration, this result is a good improvement.

\section{Funding: No funding sources}

Conflict of interest: None declared

Ethical approval: The study was approved by the Institutional Ethics Committee

\section{REFERENCES}

1. Acharya S, Yasmin E, Balen AH. The use of a combination of pentoxifylline and tocopherol in women with a thin endometrium undergoing assisted conception therapies-a report of 20 cases. Hum Fertil (Camb). 2009;12:198-203. 
2. Lebovitz O, Orvieto R. Treating patients with "thin" endometrium - an ongoing challenge. Gynecol Endocrinol. 2014;30:409-14.

3. Zinger M, Liu JH, Thomas MA. Successful use of vaginal sildenafil citrate in two infertility patients with Asherman's syndrome. J Women's Health. 2006; 15:442-4.

4. Casper RF. It's time to pay attention to the endometrium. Fertil Steril. 2011;96:519-21.

5. Revel A. Defective endometrial receptivity. Fertil Steril. 2012;97:1028-32.

6. Azizi R, Aghebati-Maleki L, Nouri M, Marofi F, Negargar S, Yousefi M. Stem cell therapy in Asherman syndrome and thin endometrium: Ste cellbased therapy. Biomed Pharmacother. 2018;102:33343.

7. Chang Y, Li J, Chen Y, Wei L, Yang X, Shi Y, et al. Autologous platelet- rich plasma promotes endometrial growth and improves pregnancy outcome during in vitro fertilization. Int J Clin Exp Med. 2015;8:1286-90.

8. Colombo GVL, Fanton V, Sosa D, Criado Scholz E, Lotti J, Aragona SE, et al. Use of platelet rich plasma in human infertility. J Biol Regul Homeost Agents. 2017;31:179-82.

9. Molina A, Sanchez J, Sanchez W, Vielma V. Platelet-rich plasma as an adjuvant in the endometrial preparation of patients with refractory endometrium. JBRA Assist Reprod. 2018;22:42-8.

10. Tandulwadkar SR, Naralkar MV, Surana AD, Selvakarthick M, Kharat AH. Autologous intrauterine platelet-rich plasma instillation for suboptimal endometrium in frozen embryo transfer cycles: a pilot study. J Hum Reprod Sci. 2017;10:208-12.

11. Jang HY, Myoung SM, Choe JM, Kim T, Cheon YP, Kim YM, et al. Effects of autologous platelet-rich plasma on regeneration of damaged endometrium in female rats. Yonsei Med J. 2017;58:1195-203.

Cite this article as: Anitha A, Rani BS. Effect of autologous platelet rich plasma on thin endometrium in frozen thawed embryo transfer. Int J Reprod Contracept Obstet Gynecol 2020;9:1079-82. 